\title{
Evidence-based follow-up in colorectal cancer-quo vadis?
}

\author{
Manuel Maglione $\cdot$ Alexander Perathoner (D)
}

Received: 19 August 2019 / Accepted: 22 November 2019 / Published online: 12 December 2019

(C) The Author(s) 2019

Summary Colorectal cancer is the third most common and the third most lethal cancer disease in the western world. As most patients undergo treatment with curative intent at initial diagnosis, postoperative surveillance protocols have been established with the primary aim to detect possible disease recurrence in an early resectable stage. Various international guidelines recommend an intensive surveillance protocol over a 5-year time period. These guidelines are based on the reported significant benefit regarding overall patient survival, and on the observation that $90 \%$ of recurrences occur within the first 5 years following resection. Surveillance protocols include regular clinical examinations, measurement of the carcinoembryonic antigen, computed tomography scans and regular endoscopies. While there is plenty of evidence regarding the scheduling of endoscopies, the frequency of carcinoembryonic antigen measurements and computed tomography scans has been ever since under debate. The benefit of intensive compared to low frequency surveillance protocols regarding disease-specific survival has never been shown. Moreover, recent meta-analyses and randomized controlled trials challenge current guidelines. Intensive carcinoembryonic antigen assessment and computed tomography scan follow-up protocols seem to fail in generating better overall and disease-specific survival in colorectal cancer patients compared to less intensive surveillance strategies. This change over the last few decades

Assoc. Prof. Priv.-Doz. Dr. M. Maglione, MBA MCI, FEBS $(\mathrm{HPB}) \cdot$ Assoc. Prof. Priv.-Doz. Dr. A. Perathoner $(\bowtie)$

Department of Visceral, Transplant, and Thoracic

Surgery, Medical University of Innsbruck,

Anichstraße 35, 6020 Innsbruck, Austria

alexander.perathoner@i-med.ac.at

Assoc. Prof. Priv.-Doz. Dr. M. Maglione, MBA MCI, FEBS (HPB)

manuel.maglione@i-med.ac.at parallels the treatment evolution of colorectal cancer from a primarily surgical to a multidisciplinary task. Instead of advocating a reduction of the follow-up intensity, these findings should stimulate the colorectal oncology field to move from a one-fits-all to a patientcentered surveillance.

Keywords Colorectal cancer · Surveillance · Followup · Guidelines · CEA · Tumor marker · Recurrence

\section{Introduction}

Colorectal cancer (CRC) represents with an overall life time risk of $4.15 \%$ in women and $4.49 \%$ in men the third most common cancer diagnosed in the western world. Despite the fact that most of the diagnosed cancers can be detected in early stages and can be therefore treated with curative intent, it is the third leading cause of cancer-related deaths [1]. Advances in diagnostic tools, surgical techniques, neoadjuvant and adjuvant systemic treatments combined in multidisciplinary approaches have broadened the indication for curative intended treatment strategies. As a matter of fact, the risk of disease recurrence increased by up to $40 \%$ at the time of treatment because more patients with advanced stages undergo successful curative treatment; the majority of recurrences occur within the first 3 to 5 years [2]. Disease recurrence might manifest itself as locoregional recurrence, distal metastasis or as a metachronous colorectal primary.

Detecting the recurrent disease in an early, resectable stage with the aim to achieve a survival improvement is the major goal of postoperative CRC surveillance protocols. In addition, curative treatment approaches by implementation of multimodal strategies in patients presenting with liver-limited or lunglimited distant metastasis (in both cases $>40 \% 5$-year 
survival) justify postoperative surveillance protocols for CRC $[3,4]$.

Other not less important goals include issues like identification of precancerous lesions which might represent precursors of metachronous CRC, diagnosis of surgery-related problems (e.g. incisional hernia, anastomotic stenosis), psycho-oncological support and last but not least audit of one's own center's data and potential impact of new therapeutic approaches [5].

Based on the observation that $90 \%$ of recurrences will occur within the first 3 to 5 years after treatment, major cancer societies like ESMO (European Society for Medical Oncology), ASCO (American Society of Clinical Oncology), NCCN (National Comprehensive Cancer Network) as well as the Austrian Society for Surgical Oncology (ACO ASSO) recommend 5 -year surveillance for CRC [6]. All the protocols resemble an intensive surveillance strategy built on four pillars: clinical examination, carcinoembryonic antigen (CEA), computed tomography (CT scans) and endoscopies performed at regular intervals.

The common intensive surveillance strategy relies on different meta-analyses and systematic reviews which showed that this strategy was associated with a better overall survival of patients following surgery for non-metastatic CRC compared to less intensive protocols [7-9]. However, many of the corresponding studies are outdated and have different shortcomings (e.g. small number of patients). A couple of recent methodologically high-quality trials have been published with consistent results showing that the expected survival benefit due to earlier detection of recurrence has not been achieved in intensive surveillance protocols. The various reduced frequency follow-up regimes analyzed by the most representative trials (COLOFOL study, GILDA study and FACS study) consisted of CT and CEA at 12 and 36 months, CEA only, CT only, CEA and CT, or symptom-based followup [10-12]. The observation that the benefit of early detection of recurrence after curative treatment of CRC does not translate into improved cancer-specific survival definitely challenge current guidelines.

\section{Clinical examination}

Clinical examination, including recent medical history, is a routine procedure in every out-patient clinic regardless of the patients' diseases. In CRC surveillance its role can be considered marginal regarding diagnosis of asymptomatic recurrences, and it might be even less in rectal cancer patients were radiation therapy does not allow any differential diagnosis between local recurrence and radiation consequences [13]. In this context, it should be mentioned that there is no evidence for performing regular fecal occult blood tests (FBOT).

The usefulness of regular examinations has to be seen in the possibility to address surgery-related prob- lems, psychological and psychosocial issues [14] and also in the better adherence to the surveillance protocol if hospitals offer dedicated outpatient clinics for CRC [15].

\section{Carcinoembryonic antigen}

The carcinoembryonic antigen (CEA) is an oncofetal antigen produced by epithelial tumor cells in the digestive tract. In general, measurement of the tumor marker CEA is recommended every 3-6 months for 5 years [6]. It represents a cheap and safe test for the follow-up of colorectal cancer patients [16].

Elevated postoperative CEA is associated with a high probability of disease recurrence; however, negative CEA does not exclude tumor recurrence [17]. In fact, up to $40 \%$ of all recurrences of colorectal cancer do not have an accompanying increase of CEA [18]. The sensitivity of CEA testing ranges from 17 to $100 \%$, while the specificity ranges from 66 to $98 \%$ in different studies [16]. A major disadvantage of CEA is the high rate of false positives (e.g. cigarette smoking), and there are also no clear data that confirm a significant impact on survival if assessed more frequently $[16,19]$. Recently, a large randomized study showed that CEA screening provides an increased rate of surgical resection of recurrence compared with minimal follow-up. However, a survival advantage was not observed [10].

\section{Imaging - computed tomography scan}

The computed tomography (CT) scan is the imaging tool of choice in follow-up of CRC. Most guidelines recommend CT scans every 6-12 months for 3 or 5 years. However, the optimal frequency of CT imaging is not clear. Frequent use does not seem to be superior to less frequent use [11]. Ultrasound has a low sensitivity, magnetic resonance imaging is rather limited to the examination of the liver, positron emission tomography is indicated only in special cases, and endosonography may help only to detect local recurrence in rectal cancer. The major advantage of CT scans of the pelvis, abdomen and thorax is the early diagnosis of asymptomatic distant recurrence, which may still be resected with curative intent, especially in liver and lung $[6,20]$. The FACS randomized clinical trial has shown that both CT and CEA were associated with an elevated rate of surgical treatment of recurrence, however, with no survival advantage. Interestingly the combination of CT and CEA did not seem to be superior to either alone [10].

Some experts argue that CT is associated with a relevant radiation exposure and a risk of new malignancies. Alternatively, chest x-ray and abdominal ultrasound can be performed to detect liver or lung metastases; an ongoing French study will provide further clarity about whether this combination is equal to CT alone [21]. 


\section{Endoscopy}

In contrast to CEA measurement and CT scans, there is less contradictory evidence for the performance of surveillance endoscopies to diagnose synchronous and metachronous CRC as well as intraluminal recurrences. Considering the reported prevalence of up to $7 \%$ of synchronous CRC [22] preoperative colonoscopy in non-obstructive disease is mandatory. The high incidence of metachronous diseases within the first year in older studies as well as retrospective collected data reflect probably overlooked lesions at the time of initial CRC diagnosis and emphasize even more the importance of preoperative endoscopy [23]. It is generally recommended to perform the first colonoscopy within the first 3 to 6 months following surgery if preoperative colonoscopy was not possible [24].

While the recurrence risk decreases over time the estimated cumulative incidence of metachronous CRC persist with $0.35 \%$ per year following curative CRC resection [22]. This is the basis for recommending the first colonoscopy one year following CRC resection (or one year following early postoperative colonoscopy in initial obstructive disease), and in case of normal findings 3 years afterwards. The interval should be shortened in case of abnormal findings like dysplastic adenomas. After completed surveillance, colonoscopies should be repeated at regular intervals according to the national CRC screening protocols [24].

Table 1 Follow-up protocol of colorectal cancer patients at the Department of Visceral, Transplant and Thoracic Surgery at the Medical University of Innsbruck based on American NCCN

\begin{tabular}{|c|c|c|c|c|c|c|c|c|c|c|c|c|c|c|c|c|c|c|c|c|c|}
\hline & \multirow[b]{2}{*}{ Months } & \multicolumn{4}{|c|}{ 1st year } & \multicolumn{4}{|c|}{ 2nd year } & \multicolumn{4}{|c|}{ 3rd year } & \multicolumn{4}{|c|}{ 4th year } & \multicolumn{4}{|c|}{5 th year } \\
\hline & & 3 & 6 & 9 & 12 & 15 & 18 & 21 & 24 & 27 & 30 & 33 & 36 & 39 & 42 & 45 & 48 & 51 & 54 & 57 & 60 \\
\hline \multirow{4}{*}{$\begin{array}{l}\text { Colon } \\
\text { Carci- } \\
\text { noma }\end{array}$} & CEA & $x$ & $x$ & $x$ & $x$ & $x$ & $x$ & $x$ & $x$ & - & $x$ & - & $x$ & - & $x$ & - & $x$ & - & $x$ & - & $x$ \\
\hline & $\begin{array}{l}\text { Clinical Examina- } \\
\text { tion }\end{array}$ & $x$ & $x$ & $x$ & $x$ & $x$ & $x$ & $x$ & $x$ & - & $x$ & - & $x$ & - & $x$ & - & $x$ & - & $x$ & - & $x$ \\
\hline & Colonoscopy & $\left(x^{a}\right)$ & - & - & $x$ & - & - & - & - & - & - & - & - & - & - & - & $x^{b}$ & - & - & - & - \\
\hline & CT scan & - & - & - & $x$ & - & - & - & $x$ & - & - & - & $x$ & - & - & - & $x$ & - & - & - & $x$ \\
\hline \multirow{5}{*}{$\begin{array}{l}\text { Rectal } \\
\text { Carci- } \\
\text { noma }\end{array}$} & CEA & $x$ & $x$ & $x$ & $x$ & $x$ & $x$ & $x$ & $x$ & - & $x$ & - & $x$ & - & $x$ & - & $x$ & - & $x$ & - & $x$ \\
\hline & $\begin{array}{l}\text { Clinical Examina- } \\
\text { tion }\end{array}$ & $x$ & $x$ & $x$ & $x$ & $x$ & $x$ & $x$ & $x$ & - & $x$ & - & $x$ & - & $x$ & - & $x$ & - & $x$ & - & $x$ \\
\hline & Colonoscopy & $\left(x^{a}\right)$ & - & - & $x$ & - & - & - & - & - & - & - & - & - & - & - & $x^{b}$ & - & - & - & - \\
\hline & CT scan & - & $\left(x^{C}\right)$ & - & $x$ & - & $\left(x^{c}\right)$ & - & $x$ & - & - & - & $x$ & - & - & - & $x$ & - & - & - & $x$ \\
\hline & Rectoscopy ${ }^{d}$ & $x$ & $x$ & $x$ & - & $x$ & $x$ & $x$ & $x$ & - & $\mathrm{x}$ & - & $x$ & - & $x$ & - & - & - & $x$ & - & $x$ \\
\hline \multicolumn{22}{|c|}{$\begin{array}{l}\text { In case of curative treatment of distant metastases, CT scan } \\
\text { for further } 5 \text { years } \\
\text { CEA carcinoembryonic antigen, CT computed tomography } \\
\text { alf not performed preoperatively } \\
\text { bIf normal findings to be repeated regularly according to nat } \\
\text { CIn high-risk patients (G III, L pos, V pos) }\end{array}$} \\
\hline
\end{tabular}

\section{Additional aspects}

It has to be highlighted that current international guidelines are based on data of patients operated on UICC stage II and III CRC. The expert guidelines do not particularly consider UICC stage I and IV because consistent data are missing. Over 95\% of patients with UICC stage I are cured with surgery and do not need adjuvant chemotherapy. Consequently, the recurrence rate is minimal and intensive surveillance seems to be dispensable. In patients with UICC stage IV with an obvious high risk of recurrence of metastases, studies have demonstrated on the contrary that intensive 3-monthly surveillance with CT after hepatic resection is reasonable and improves outcome [25]. Similarly, patients with hereditary syndromes (e.g. Lynch syndrome) also need more frequent surveillance to detect recurrence and additional tumor manifestations [26]. The follow-up of patients with rectal cancer has become particularly challenging because of new treatment options emerging recently. Local T1 tumor resection or watch and wait concepts demand an intensive follow-up approach (e.g. endoscopy every 3 months for 2 years) until representative data about less intensive surveillance are published.

\section{Conclusion}

Recent trials and meta-analyses challenge current CRC surveillance guidelines. Intensive approaches to surveillance are expensive, but facilitate early detection of recurrence after curative treatment of colorectal cancer. On the other hand, this benefit and less intensive approaches to surveillance do not seem to

Guidelines, European ESMO Guidelines and Austrian ACOASSO Guidelines 
be inferior. However, the current recommendation is still an intensive surveillance protocol over a 5-year time period (Table 1). Reduced-frequency surveillance protocols should only be offered in the setting of clinical trials.

Rather than encouraging a reduction of postoperative surveillance examinations the ongoing controversy should stimulate further evolution of patientcentered and stage-adapted surveillance protocols in the light of increasing knowledge of molecular, immunological and microbioma-associated aspects known to influence patients' outcome.

\section{Take-home message}

Current guidelines recommend intensive surveillance postoperative protocols based on regular clinical examinations, measurements of CEA, CT scans and endoscopies. Recent data challenge these surveillance protocols and call for more patient-centered and stageadapted protocols.

Funding Open access funding provided by University of Innsbruck and Medical University of Innsbruck.

Conflict of interest M. Maglione and A. Perathoner declare that they have no competing interests.

Open Access This article is distributed under the terms of the Creative Commons Attribution 4.0 International License (http://creativecommons.org/licenses/by/4.0/), which permits unrestricted use, distribution, and reproduction in any medium, provided you give appropriate credit to the original author(s) and the source, provide a link to the Creative Commons license, and indicate if changes were made.

\section{References}

1. Ferlay J, Colombet M, Soerjomataram I, Dyba T, Randi G, Bettio M, et al. Cancer incidence and mortality patterns in Europe: estimates for 40 countries and 25 major cancers in 2018. Eur J Cancer. 2018;103:356-87.

2. Pfister DG, Benson AB, Somerfield MR. Clinical practice. Surveillance strategies after curative treatment of colorectal cancer. NEngl J Med. 2004;350(23):2375-82.

3. Kanas GP, Taylor A, Primrose JN, Langeberg WJ, Kelsh MA, Mowat FS, et al. Survival after liver resection in metastatic colorectal cancer: review and meta-analysis of prognostic factors. Clin Epidemiol. 2012;4:283-301.

4. Gonzalez M, Poncet A, Combescure C, Robert J, Ris HB, GervazP. Riskfactors for survival after lung metastasectomy in colorectal cancer patients: a systematic review and metaanalysis. Ann Surg Oncol. 2013;20(2):572-9.

5. Destri LG, Di Cataldo A, Puleo S. Colorectal cancer followup: useful or useless? Surg Oncol. 2006;15(1):1-12.

6. Liu SL, Cheung WY. Role of surveillance imaging and endoscopy in colorectal cancer follow-up: quality over quantity? World J Gastroenterol. 2019;25(1):59-68.

7. Pita-Fernández S, Alhayek-Aí M, González-Martín C, López-Calviño B, Seoane-Pillado T, Pértega-Díaz S. Intensive follow-up strategies improve outcomes in nonmetastatic colorectal cancer patients after curative surgery: a systematic review and meta-analysis. Ann Oncol. 2015;26(4):644-56.
8. Renehan AG, Egger M, Saunders MP, O’Dwyer ST. Impact on survival of intensive follow up after curative resection for colorectal cancer: systematic review and meta-analysis of randomised trials. BMJ. 2002;324(7341):813.

9. Jeffery M, Hickey BE, Hider PN. Follow-up strategies for patients treated for non-metastatic colorectal cancer. Cochrane Database Syst Rev. 2007; https://doi.org/10. 1002/14651858.CD002200.pub3.

10. Primrose JN, Perera R, Gray A, Rose P, Fuller A, Corkhill A, et al. Effect of 3 to 5 years of scheduled CEA and CT followup to detect recurrence of colorectal cancer: the FACS randomized clinical trial. JAMA. 2014;311(3):263-70.

11. Wille-Jørgensen P, Syk I, Smedh K, Laurberg S, Nielsen DT, Petersen SH, et al. Effect of more vs less frequent follow-up testingonoveralland colorectal cancer-specificmortalityin patients with stage II or III colorectal cancer: the COLOFOL randomized clinical trial. JAMA. 2018;319(20):2095-103.

12. Rosati G, Ambrosini G, Barni S, Andreoni B, Corradini G, Luchena $\mathrm{G}$, et al. A randomized trial of intensive versus minimal surveillance of patients with resected Dukes B2-C colorectal carcinoma. Ann Oncol. 2016;27(2):274-80.

13. Anthony T, Simmang C, Hyman N, Buie D, Kim D, Cataldo P, et al. Practice parameters for the surveillance and follow-up of patients with colon and rectal cancer. Dis Colon Rectum. 2004;47(6):807-17.

14. Stiggelbout AM, de Haes JC, Vree R, van de Velde CJ, Bruijninckx CM, van Groningen K, et al. Follow-up of colorectal cancer patients: quality of life and attitudes towards follow-up. Br JCancer. 1997;75(6):914-20.

15. Coebergh van den Braak RRJ, Lalmahomed ZS, Büttner S, Hansen BE, Ijzermans JNM, Group MS. Nonphysician clinicians in the follow-up of resected patients with colorectal cancer. Dig Dis. 2018;36(1):17-25.

16. Sørensen CG, Karlsson WK, Pommergaard HC, Burcharth J, Rosenberg J. The diagnostic accuracy of carcinoembryonic antigen to detect colorectal cancer recurrence-a systematic review. Int J Surg. 2016;25:134-44.

17. Nicholson BD, Shinkins B, Pathiraja I, Roberts NW, James TJ, Mallett S, et al. Blood CEA levels for detecting recurrent colorectal cancer. Cochrane Database Syst Rev. 2015; https://doi.org/10.1002/14651858.CD011134.pub2.

18. Benson AB, Desch CE, Flynn PJ, Krause C, Loprinzi CL, MinskyBD, etal. 2000 update ofAmerican Society ofClinical Oncology colorectal cancer surveillance guidelines. J Clin Oncol. 2000;18(20):3586-8.

19. Treasure T, Monson K, Fiorentino F, Russell C. The CEA Second-Look Trial: a randomised controlled trial of carcinoembryonic antigen prompted reoperation for recurrent colorectal cancer. BMJ Open. 2014;4(5):e4385.

20. Chau I, Allen MJ, Cunningham D, Norman AR, Brown G, Ford HE, et al. The value of routine serum carcino-embryonic antigen measurement and computed tomography in the surveillance of patients after adjuvant chemotherapy for colorectal cancer. JClin Oncol. 2004;22(8):1420-9.

21. Lepage C, Phelip JM, Cany L, Faroux R, Manfredi S, Ain JF, et al. Effect of 5 years of imaging and CEA follow-up to detect recurrence of colorectal cancer: the FFCD PRODIGE 13 randomised phaseIII trial. DigLiver Dis. 2015;47(7):529-31.

22. Kahi CJ, Boland CR, Dominitz JA, Giardiello FM, Johnson DA, Kaltenbach T, et al. Colonoscopy surveillance after colorectal cancer resection: recommendations of the US multi-society task force on colorectal cancer. Gastroenterology. 2016;150(3):758-68.e11.

23. le Clercq CM, Winkens B, Bakker CM, Keulen ET, Beets GL, Masclee AA, et al. Metachronous colorectal cancers result frommissedlesionsand non-compliancewith surveillance. GastrointestEndosc. 2015;82(2):325-333.e2. 


\section{short review}

24. Rex DK, Kahi CJ, Levin B, Smith RA, Bond JH, Brooks D, et al. Guidelines for colonoscopy surveillance after cancer resection: a consensus update by the American Cancer Society and US Multi-Society Task Force on Colorectal Cancer. CA Cancer JClin. 2006;56(3):160-7. quiz85-6.

25. Gomez D, Sangha VK, Morris-Stiff G, Malik HZ, Guthrie AJ, Toogood GJ, et al. Outcomes of intensive surveillance after resection of hepatic colorectal metastases. Br J Surg. 2010;97(10):1552-60.

26. Giardiello FM, Allen JI, Axilbund JE, Boland CR, Burke CA, Burt RW, et al. Guidelines on genetic evaluation and management of Lynch syndrome: a consensus statement by the US Multi-society Task Force on colorectal cancer. Am J Gastroenterol. 2014;109(8):1159-79.
Publisher's Note Springer Nature remains neutral with regard to jurisdictional claims in published maps and institutional affiliations.

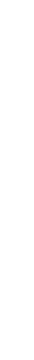

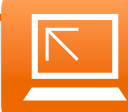

- For latest news from international oncology congresses see: http://www.springermedizin.at/ memo-inoncology 